\title{
Balkanologie
}

Balkanologie Revue d'études pluridisciplinaires

Vol. VI, $n^{\circ}$ 1-2 | 2002

Volume VI Numéro 1-2

\section{Radost (Ivanova), Folklore of the Change. Folk Culture in Post-Socialist Bulgaria}

Helsinki: Academia Scientiarum Fennica, 1999 [= FF Communications, $\left.123_{2},(270)\right], 127$ pages

\section{Galía Valtchinova}

\section{OpenEdition}

\section{Journals}

Édition électronique

URL : http://journals.openedition.org/balkanologie/1862

DOI : 10.4000/balkanologie.1862

ISSN : 1965-0582

\section{Éditeur}

Association française d'études sur les Balkans (Afebalk)

\section{Édition imprimée}

Date de publication : 1 décembre 2002

Pagination : 278-280

ISSN : 1279-7952

\section{Référence électronique}

Galía Valtchinova, "Radost (Ivanova), Folklore of the Change. Folk Culture in Post-Socialist Bulgaria »,

Balkanologie [En ligne], Vol. VI, n 1-2 | 2002, mis en ligne le 04 février 2009, consulté le 17 décembre 2020. URL : http://journals.openedition.org/balkanologie/1862 ; DOI : https://doi.org/10.4000/ balkanologie. 1862 
dernier, intitulé " Restitutions rurales ", examine la détail les causes profondes du rejet que la société locale oppose à la nouvelle politique agricole menée à partir de 1992-1993 : elle s'attaque à un système déjà bien “domestiqué” qui n'a plus grand-chose à voir avec les coopératives des années 1940 et 1950. C'est ainsi que l'auteur explique, également, la préférence des locaux pour le parti socialiste (ex-communiste) bulgare et leur "vote rouge". La conclusion étend les observations sur la continuité (réelle et/ou perçue) entre réformes "socialistes" et transition post-communiste à une réflexion sur les relations sociales et les changements durables au niveau des mentalités ("Égalités" et "Identités rurales", pp. 265-276). Le livre de Gerald Creed donne une explication logique et claire à des processus et à des phénomènes de la "transition post-communiste" qui persistent à être une source de malaise autant pour la démocratie bulgare que pour beaucoup d'experts locaux et internationaux en politique ou en sciences sociales.

Galia Valtchinova

\author{
Radost (Ivanova), \\ Folklore of the Change. Folk Culture in Post-Socialist Bulgaria. \\ Helsinki : Academia Scientiarum Fennica, 1999 \\ [= FF Communications, $\left.123_{2},(270)\right], 127 \mathrm{p}$.
}

Ce livre est une réponse spécifique, celle de l'ethnologue et du folkloriste ${ }^{11}$, aux événements et aux processus de changements politiques en Bulgarie entre 1989 et 1996. Il capte, décrit et donne une première analyse à quelques-uns des aspects les plus saillants d'une culture balkanique lors du passage, non-révolutionnaire (au sens marxiste du terme) d'un système social à un autre. Composé de huit études sur des sujets distincts, mais clairement reliés entre eux, le livre présente un double défi : d'un côté, scruter la dynamique des processus culturels lors de l'ouverture démocratique et libérale de la société bulgare, détectant les premiers signes de changement des mentalités. De l'autre côté, identifier les formes à une "culture de la transition" à part entière [kultura na prehoda], s'interrogeant sur les promesses et les dangers qu'elle contient.

Intitulé "Le chemin vers la démocratie ", le premier chapitre (pp. 17-27) explore les dimensions spatiales des protestations politiques de masse. Il s'agit de juxtaposer deux concepts alternatifs de "centre" et de "cité" - en l'occurrence, le cœur administratif de la capitale Sofia et la "Cité de la Vérité" du printemps de $1990^{12}$ - et le fonctionnement du déplacement même de la périphérie vers le "centre" comme une quête de la démocratie. La ritualisation de la marche et de l'espace parcouru par des manifestants est un sujet présent, également, dans la deuxième contribution (pp. 28-37), cependant focalisée sur les slogans. L'auteur a choisi pour intitulé du chapitre (qui est le titre du livre dans sa version bulgare) l'un des slogans les plus savoureux de ces années : "Au revoir, dinosaures, bienvenus, crocodiles! ". Formules écrites pour être portées sur des transparents ou bien paroles prononcées, scandées, les slogans sont comparables à l'anecdote politique si vivace sous le socialisme,

${ }^{11}$ L'expression est empruntée à la préface de Klaus Roth, p. 5.

12 Campement d'intellectuels et d'étudiants, soutenu par plusieurs députés de l'opposition, face à la Présidence, pour protester contre les tentatives de freiner le renouveau démocratique et les insuffisances de la nouvelle Constitution. 
tout en étant très différents dans la manière de leur communication. Multipliant les exemples visant à montrer la place des slogans dans la culture publique dite « de changement politique " (voir aussi les chapitres 3, 5 et 6), R. Ivanova les définit comme un genre proche de l'incantation (pp. 65-67), ou comme " forme spécifique de folklore " (pp. 32-33). Elle montre l'utilité de l'étude de cette "expression de masse" aussi bien pour les folklore studies et la socio-linguistique que pour l'histoire sociale et l'histoire des mentalités.

La troisième des contributions (pp. 38-55) porte le sous-titre " Le drapeau comme système de signes dans la culture bulgare ". Elle s'articule autour de deux thèmes : un premier, celui de la signification de l'objet - et du symbole - appelé drapeau ; un second concernant le symbolisme des couleurs et leur interprétation changeante. Une section consacrée au drapeau dans le mariage traditionnel bulgare met ces deux thèmes en rapport, grâce à une approche sémiotique. Un détour par la question des drapeaux nationaux et de leur importance symbolique grandissante dans la société moderne permet de faire le point sur les façons de "lire la couleur" décrétées par l'Etat national et centralisateur. Avec l'amplification de la contestation politique, les drapeaux de partis politiques (bleu, vert, rouge etc.) tendent à se substituer au tricolore national ou tout au moins à radicalement altérer la lecture qui est habituellement donnée de la couleur rouge.

Une autre expression savoureuse empruntée, cette fois, non à la rue, mais à une parodie de parti politique, l'Union des Forces Sexuelles, introduit le thème de la subversion des textes et des mots d'ordre politiques (pp. 56-63). Pleine d'humour et de verve, une "pétition" de 1990 tourne en dérision la prolifération de nouvelles formations politiques, accompagnant les noms de quelques-unes des plus connues de l'adjectif "sexuel/le/s". Afin de remonter à la source de cette pratique, la folkloriste bulgare se tourne vers un des premier décrets soviétiques de mars 1918 proclamant l'" abolition de la propriété privée sur la femme ". Pourtant, une tournure comme "Camarades, Mesdames et Messieurs... Bulgares n traduit le désarroi de toute une culture d'expression publique et d'adresse face au basculement des valeurs et au changement des repères politiques. On peut regretter que cette réflexion ne soit pas explicitée et développée, d'autant plus que les événement récents montrent que le même problème continue à se poser à chaque détour imprévu du chemin menant vers "la démocratie". Cette formule semble toujours de mise en 2001 lorsque, après la victoire du Mouvement National Siméon Deux aux élections législatives, médias et élites politiques bulgares se confondirent, dans leur terminologie, d'adresse vis-à-vis du nouveau Premier ministre : Monsieur, Citoyen ou Majesté ? Post factum, cet exemple fait voir toute l'importance de la recherche sur les formes de communication et de sociabilité publiques.

Un autre aspect de la culture du changement est évoqué dans le sixième chapitre (pp. 71-87) : les graffiti sur certains lieux de mémoire de l'époque communiste : le Monument à l'Armée rouge, le mausolée de G. Dimitrov (rasé en 1999). La culture des graffiti étant quasiment inexistante sous le socialisme, il est d'autant plus significatif que ses premières manifestations sont associées à un extrémisme qui choque, à la fois culturel et politique. $R$. Ivanova considère la production de graffitis comme une "soupape des tensions politiques existantes " (p. 75). L'étude effectuée parmi les auteurs de graffitis montre qu'il s'agit, pour eux, de mettre l'expression publique du mécontentement à la portée de tous, d'introduire les attitudes de protestation dans des espaces réservés à ce qu'on peut appeler la culture du silence respectueux, et d'effectuer une sorte de contrôle continu sur les hommes politiques les plus en vue. Ce dernier objectif est manifeste dans un slogan repris par les graffitis et que l'auteur a choisi comme intitulé du chapitre : "Toutes les grenouilles sont vertes, seule la nôtre est rouge ! ". L'allusion au premier président démocratiquement élu, Z. Zhelev, est transparente. Un florilège de graffiti à contenu politique assez âpre, destinés aux leaders, est à découvrir aux pages 81-86. 
A l'affût des changements de mentalités, R. Ivanova ne pouvait manquer rendre compte d'un phénomène très marquant des années 1990 : la récupération politique des sports de combat et la tendance généralisée à faire de l'appellation de certains sports un synonyme de "mafieux". Le texte témoigne d'une fine observation du rapprochement, au niveau des significations et du symbolisme, entre "lutteur", "garde-du-corps", "sale gueule" [mutra], "truand" - tous devenus des figures contemporaines du "héros"13. La documentation se diversifie : à côté de l'anecdote qui marque son retour, c'est la presse écrite - désormais très influencée par le langage parlé et expressif - qui apparait comme l'indicateur d'une nouvelle oralité exubérante.

Replacé dans le contexte de l'ethnologie et de la science du folklore, telles qu'elles étaient pratiquées jusqu'à tout récemment dans les Balkans et en Europe de l'Est, ce livre est sans doute un ouvrage novateur. Il est résolument tourné vers la ville, les grandes urbanités (ce n'est que dans le dernier chapitre que s'opère le retour vers le village) ; il présente des processus socio-politiques récents ou en cours, représentatifs du changement du système politique et d'un société en transition; enfin, il met à contribution une documentation rarement prise au sérieux par les autres sciences sociales ou l'histoire, et réussit à en extraire le maximum. A tous ceux qui n'aiment pas les folklore studies, il fournit un matériau abondant et utile, autant pour l'historien que pour l'ethnologue ou le politologue.

Galia Valtchinova

\author{
Nikolov [Rajko], \\ Diplomacija na četiri oči. Iz dnevnika na edni bălgarski poslanik v \\ Jugoslavija [Diplomatie entre quatre-z-yeux. Extraits du journal d'un \\ ambassadeur bulgare en Yougoslavie], \\ Sofia : Lik, 1999, 304 p.
}

Les souvenirs, mémoires et journaux intimes, qui sont, de plus en plus nombreux à paraître, nous ouvrent des perspectives sur des aspects de la période communiste qui paraissaient fort opaques aux observateurs étrangers. La manie du secret voilait de mystère des événements ou des enjeux, dont nous commençons à prendre les véritables dimensions. Les notes de Rajko Nikolov nous permettent ainsi de mieux cerner les relations inter balkaniques, lors d'une période relativement calme, à savoir les années 1978-1983. Etre ambassadeur de Bulgarie à Belgrade à cette époque n'est pas une position enviable. La Bulgarie ne cesse en effet de clamer publiquement que, grâce au socialisme, ses problèmes de voisinage sont résolus, tandis que la Yougoslavie ne perd pas une occasion pour dénoncer le nationalisme de sa voisine à propos de la question macédonienne. Situation paradoxale qui oblige l'ambassadeur à avaler maintes couleuvres... Le paradoxe est décortiqué minutieusement au long du livre. La politique balkanique de la Bulgarie est menée directement par Todor Živkov (Petăr Mladenov, ministre des Affaires étrangères apparait comme un personnage extraordinairement falot) qui, pour des raisons idéologiques, ne peut en aucun cas se démarquer ni s'opposer à la ligne politique de Georgi Dimitrov, la grande icône du communisme bulgare. Or ce dernier avait, lors des rencontres de Bled et d'Evksinograd en 1947, reconnu l'existence

13 Un constat à comparer aux observations, faites à partir du cinéma yougoslave, de Iordanova (Dina), Cinema of Flames. Balkan Film, Culture and the Media. London : BFI Publishing, 2001, pp. 178-181. 